


\title{
"Leading" as a mode of interaction and communication in contemporary music performance-practice
}

\begin{abstract}
INTRODUCTION
"Leading" in this context refers to directing or conducting a music ensemble with physical indications while playing an instrument. Leading gestures are used to guide, cue and synchronise ensemble playing both in chamber music ensembles and in conductor-directed ensembles. ${ }^{1}$ While still a student, I joined a newly-founded contemporary music ensemble, Uusinta Ensemble. When it was my turn to lead, I realised that despite my chamber music studies, I was unable to lead contemporary music. With the help of my fellow musicians, I was able to gradually acquire leading skills. I learned that leading a contemporary chamber music work could be physically strenuous, difficult or impossible even for professional musicians. Learning to lead also taught me to follow, support and understand other musicians' leading. These skills have been beneficial in all of my playing and teaching of contemporary music. Since I have no training in conducting, my leading gestures are based on gestural images and my understanding of conducting patterns as a violinist and orchestra musician.

In this article, I aim to explicate my tacit knowledge as a violinist and leader through practice-based research. My research questions are: What kind of leading techniques are used to express different musical features when leading chamber ensembles in contemporary music? What factors affect leading? I reflect on my own leading in three case studies through my rehearsal diary, video recordings and score annotations as well as referring to research literature.
\end{abstract}

\section{WHY IS LEADING CONTEMPORARY MUSIC DIFFICULT?}

In the second half of the 20th century contemporary music compositions became more complex. The structures of compositions were based on different principles than in tonal music: polyrhythmic temporal structure, constantly changing metri-

1 Leaders in conductor-directed ensembles relate their leading to the conductor's gestures and synchronise their temporal and expressive playing styles with other leaders and within their own group (Lipinaityte 2014, 70). In this article, I will focus on musician-led ensembles. 
cal organization, free tonal or atonal harmonic structures and extreme tone colours (Johnston 2006, 89-102). Due to their versatile expressive and technical demands, extended playing techniques, new notations and tuning systems, microtones and electronics, many contemporary music works became extremely difficult to play (Caruso et al. 2016, 403; Griffiths, 2011).

In terms of achieving a successful performance of contemporary music, how to lead became a critical question. Due to the complexity of the musical material and the temporal alignment, leading contemporary chamber music is often more demanding than leading the traditional Classical-Romantic repertoire. Often there is no clearly audible pulse or rhythmic and harmonic pattern to help musicians synchronise their ensemble playing through aural information. Especially in the beginning of a rehearsal period, leading gestures are needed to show the pulse and beats. Leading may feel physically strenuous, however, since leading gestures cannot be measured to their correct pace and amplitude with the help of the pulse, rhythm or tonal harmonic functions. Furthermore, the specificities involved in the physical requirements of extended playing techniques may constrain leading gestures.

Typically, the beginning of the learning process of a new work requires visual and gestural interaction as well as information about the musical structure. ${ }^{2}$ Often there are neither recordings nor a shared performance practice for the work, and the performance may frequently be the world premiere. Mistakes in leading consequently affect ensemble playing, synchronisation and the performance as a whole. To solve this problem, even works composed for a small ensemble are often performed with a conductor, whose conducting technique is dedicated to expressing and balancing the musical structure of a work through their hands, facial expressions and body movements (Holden 2003, 3-16; McElheran 1966, 9-12). The leader's or concertmaster's task is to communicate the conductor's gestures to the ensemble through their own sound and body language (Lipinaityte 2014,73). Whether to play with a conductor or not depends on the amount of practice time, the leading experience of the musicians, and the style and aesthetic concept of the music: whether it is a reduced large ensemble or a dedicated chamber music ensemble.

\section{THE STATE OF THE ART: THE ELEMENTS AND RAMIFICATIONS OF LEADING}

In addition to sonic interaction, an expressive performance also includes gestures as tools for interaction and communication. A performer is in interaction with herself, the work, the other musicians, the audience and the venue via gestures. King and

2 In this article, musical structure refers to the played, heard and notated structure of the work as it is perceived both aurally and visually. 
Ginsborg $(2011,179)$ divide the performer's physical gestures into three categories according to the functions of their technical, expressive and communicative gestures. According to these scholars, gestures have two major functions: to technically produce sound and to convey the expressive content of the work. Different gestures are multifunctional and by nature intertwined, and therefore both technical and expressive gestures may be utilised as communicative gestures between the performers or the performers and the audience. However, a listener may not be able to perceive the exact content of a gesture since various musical, cultural, societal and environmental features as well as subjective audible and visual perceptions can affect the listener's interpretation of the gestures (ibid. 179). Moreover, gestural interaction includes intentional, rehearsed, and agreed-upon gestures as well as non-intentional gestural communication (ibid. 177).

To share notational information, the senses, playing and leading gestures, and instrument movements are used simultaneously to send and receive information in the form of body gestures and facial expressions, instrument movements, breathing, listening and reacting to aural information, both direct and peripheral gaze and "sensing others" (Boyle 2015, 11-13, 54-55). Musicians' gestures are related to the played, heard and notated musical structure, different performance styles (Demos et al. 2017, 16) and performance tempi (Coorevits et al. 2019, 102-103) of the piece performed. Temporal coordination in the ensemble is based on auditory and visual cues (Timmers et al. 2014, 6-7), and the information on timing and beat placement is encoded in musicians' cueing gestures (Bishop \& Goebl 2018, 102-103). In terms of embodied cognition, the synchronisation is a consequence of the sensorimotor entrainment process, which helps musicians to adapt to the rhythms and interact in a stable timing frame (Leman 2016,120). A musician's personal gestural styles form a movement vocabulary that can be used in variable ways to achieve similar expressive goals (Davidson 2012, 613).

The embodied, multidirectional musical interaction, gestural communication, synchronisation and diverse social roles and leadership in chamber music ensembles have been researched by multiple methods. Various studies based on the exact measurements of the musicians' gestures help to clarify their motor implementation (Bishop \& Goebl 2018; Demos et al. 2017; Timmers et al. 2014). Interviews (Blum 1987; Boyle 2015; Fink \& Merriell 1985; Murnighan \& Conlon 1991), ethnographic (Bayley 2011) and practice-based artistic research (Doğantan-Dack 2013; Heyde 2012; Spissky 2017) provide a performer's knowledge of musical interaction, interpretation and intentions behind their gestures. Combining these different approaches of quantitative and qualitative research methods have enhanced the methodological development of artistic research and provided valuable information on musicians' movements and intentions from the first-person perspective (Caruso et al. 2016; Coorevits et al. 2019; Östersjö 2016).

The "discursive voices" of the embodied and socio-culturally-situated individual 
"voices" of the performer(s) and the composer are engaged with notation, instruments, compositional and performance practices and shared contexts (Gorton \& Östersjö 2019, 2020). The rehearsal of the Kreutzer string quartet with the composer Michael Finnissy, for example, reveals the use of different types of verbal and nonverbal communication methods as well as the significance of metaphorical language used by the composer when discussing the desired sound quality with the performers (Bayley 2011,399-402). The corporeal interaction and communication among the musicians creates the choreography for the embodied, temporal, expressive and visual structure of the work, which facilitates the musicians' process of playing together and anticipating the forthcoming musical content (Heyde 2012) and enables the audience to follow the narrative of the work (Davidson 2012, 618; Leman 2016, 159-160).

One example of the ensemble leader's gestural possibilities in guiding and shaping the interpretation is provided by the violinist Peter Spissky (2017). As an ensemble leader, he explores how instrument and bow use as well as bodily gestures express both structural features and mimetic actions or dance movements. Hence, Spissky approaches the interpretation and performance-practice of Baroque music through two different interpretive strategies: the Soundist and Gesturist approaches (ibid. 1.1.2). A Soundist performer realises the score through playing gestures, dynamics and articulation that avoid unnecessary movements and aim to produce the optimal sound. For a Gesturist performer, the body's movements are an integral part of the performance, and the score itself is translated into body movements that describe the musical narrative of the work with such examples as horse riding, sword fighting or throwing (ibid. V1aT4, 5.3). The expressive and theatrical body movements in the Gesturist performance provide both the ensemble and the audience with new ways to communicate and experience music (ibid. 5.2).

In this study, I explore the musical, gestural, visual, audible, social and interactive elements of leading through my own practice in leading and with the aid of these different but complementary views. My understanding of expressive, multisensory interaction with music is based on the theory of expressive alignment as a method of enactment (Leman 2016, 180). In expressive alignment, an arrangement of musical and action patterns is based on culturally learned expressive codes (ibid. 155). The enactment process consists of encoding and decoding processes based on predictive models of action which enable the transformation of musical intentions into sound patterns through bodily gestures (ibid. 26-32). Predictive models of action allow for the chunking of information in larger units and its rapid processing (ibid. 134-135). I approach leading as a multidirectional, multimodal and crossmodal interactive process in which the predictive models of action and the enactment process are based on audible and visual perceptions of musical structures and other musicians' interactions. Predictive models of action are based on learned leading patterns and gestures in relation to a given score. In multidirec- 
tional interaction, the musical and gestural information is encoded, sent, received, and decoded among the performers.

\section{LEADERSHIP AND TEAM ROLES IN ENSEMBLES: DESIGNATED OR SHARED, STABLE OR VARIABLE, STANDARD OR EXTENDED}

A musical work does not begin without someone leading a cueing gesture for the starting tempo and the placement of the first beat. Ensembles playing improvised music may not have a need for such designated leadership, but those that play scored music usually have to define their musical team roles. For example, in her study on student quartets, King (2006, 273-276) identified several musical ensemble roles, such as leader, deputy-leader, contributor, inquirer and "a quiet one". Based on the language used in my practice with different ensembles, I define the musical team roles as leader, co-leader and follower. Next, I provide various aspects of each team role and its function in different ensembles.

Ensembles conceptualise their leadership and team roles differently. An ensemble with a designated leader coordinates its musical actions according to the leader's playing and gestures. When leadership is shared, the co-leaders take up the leading responsibility when the main leader is not playing or cannot lead due to her playing a difficult passage. Sometimes the player who is not playing leads the difficult passages to help maintain the pulse or to show entries, exits or upbeats. Furthermore, co-leaders might join in to indicate major upbeats or to support the leader with pulsating gestures (see Boyle 2015, 5). Good leader skills include "an ability to demonstrate musical intentions" (Mota et al. 2017, 178); therefore, the ability to lead also improves co-leading skills. In addition to leader and co-leader roles, an ensemble member may be a follower, which is by no means a passive role. A follower may support the leader and other musicians with synchronised body gestures and playing manners: musicians synchronise their movements by simulating others' actions, and thus good following skills include flexibility and the ability to blend in with the playing styles of the other musicians (Mota et al. 2017, 178, 183). When leadership is shared, the other team roles are also variable and alternate among the ensemble members, which may demand more verbal communication when sharing separate leading tasks.

Next, I provide some examples of how leadership and team roles are shared in different ensembles and how that influences musical outcomes. In general, string quartets provide a fascinating framework for studies on leadership and other musical team roles, with studies suggesting that the paradox between leadership and democracy (Murnighan \& Conlon 1991, 169-170) may increase the risk for both musical and social conflict, especially in string quartets (Young \& Colman 1979, 13). Today, the traditional leadership position of the first violinist (Murnighan \& 
Conlon 1991, 166, 174; Young \& Colman 1979, 15) has transitioned towards shared and alternating leadership in string quartets (Bayley 2011,395; Blum 1987, 8; Boyle 2015, 4-5; Fink \& Merriell 1985, 15). This has had a great impact on musical results: whether the ensemble divides the roles into leader/follower or shares the leadership and attempts to "play together, and not follow" (as stated by the Quarneri String Quartet's cellist David Soyer in Fink \& Merriell 1985, 22) influences the sense of timing and quality of sound. For example, in a study by Timmers et al. $(2014,7)$, the mean asynchronies in tone onsets revealed differences between the leader/follower roles in string quartets: the first violin and the cello came in relatively early, whereas the second violin and viola entered relatively late. Therefore, to implement the equally challenging musical demands of the score, leadership in professional string quartets is typically subtly shared and variable rather than stable and standard (see Boyle 2015, 5).

The instrumentation and experience of the ensemble may have a significant effect on the distribution of the leadership and team roles. When studying three student quartets consisting of different instruments, King (2006, 273-276) found that the string quartet maintained more stable and standard disposition of leadership and musical team roles than the wind and saxophone quartets, which represented more variable and extended team roles and shared leadership. Her observation of the team roles in wind and saxophone quartets is in line with a study by Ford \& Davidson $(2003,62-63)$, who found that wind quintets mostly consider the leadership as a democratically shared task among the members, although the flutist seems to be the leader in most cases. However, experience seems to be the most crucial factor in sharing leadership and ensemble roles. Studies show a significant difference between student ensembles learning to lead and collaborate socially (King 2006, 280) and professional ensembles, such as a piano trio sharing leadership depending on the musical material (Doğantan-Dack 2013,282), and string quartets with standard personnel (Boyle 2015, 6) functioning as effective self-managed teams setting their own goals even without a designated leader (Gilboa \& Tal-Shmotkin 2010, 32-33).

In addition to the factors discussed above, instrumental and interactive affordances ${ }^{3}$ influence leadership and team roles. Musicians' control processes depend on their instrumental affordances and the movements involved in playing them (Gorton \& Östersjö 2019, 41-42; MacRitchie et al. 2017, 155; Östersjö 2016, 475), which affects musicians' gestures, facial expressions and reactions and sets limits and possibilities for leading and interaction. The visible elements of string playing techniques, such as movements of the hands, fingers, arms, the instrument, and bow, share information on playing techniques, sound production, articulation and syn-

3 In this article, instrumental and interactive affordances refer to different possibilities and resistancies that performers have in different contexts. For example, an instrument affords each performer different musical possibilities and resistancies (Gorton \& Östersjö 2019, 42). 
chronisation in ensemble playing (Boyle 2015, 98-99, 116-118). This is significantly different from wind players, who use mouth and breathing to play their instruments, which also reduces the number of facial expressions (Davidson 2012, 614), as well as from singers, whose sound production is invisible and occurs inside the body (Ford \& Davidson 2003, 64). However, singers, cellists, pianists, and percussionists have nothing covering their face or mouth and thus have more capacity to show facial expressions than violinists and violists, who are leaning their chin on the chin rest.

In traditional Western classical music, the solo voices have often been composed for violin or flute; therefore, violinists and flutists are educated to take up the leader's role. Furthermore, both instruments and the violin bow are light to move and easy to see since they are held up high. Violinists and flutists are frequently seated in the "concertmaster position" on the left side of the ensemble or on the "wings" of the half circle ensemble, where fellow musicians can clearly see their movements (Ford \& Davidson 2003, 63)

In addition to traditional practices in music, modern technology may also have a significant effect on musicians' interactive affordances. Huovinen and Rautanen (2020,105-106) explored the interactive affordances of traditional band instruments and tablet computers and their effect on creativity in groups formed by children as measured in terms of ensemble performance and composition. Groups playing traditional band instruments included more creative interaction and peer teaching than the tablet computer groups, whose creative processes were more individual and contained fewer interactive gestures and playing together. Even the musical results were different: the compositions of the tablet groups contained no melodic themes but had a constant pulse that was influenced by the software.

The size of the ensemble may have a great impact on whether leadership is designated or shared (Doğantan-Dack 2013, 282). In mixed ensembles, musical and social interaction takes place among varied instrumentalists, and there are various possibilities for seating positions and gazing directions. The increased size of the ensemble and the distance between the musicians affect the amplitude and coordination of the gestures, especially if the vision of the other members is restricted and audibility diminished (MacRitchie et al.2017, 155). To be able to lead, follow and play together, musicians have to learn each other's diverse gestural styles (Mota et al. 2017, 182). Furthermore, various socio-cultural and emotional aspects affect the group dynamic (Good \& Davidson 2002,188), which has a great impact on the working atmosphere, mutual trust and courage to try out musical ideas and gestural actions.

To sum up, the roles of the leader, co-leader and follower appear to depend on musical material and practical aspects, such as seating, visibility and audibility among the players, as well as instrumental and interactive affordances, such as personal leading skills, experience and ability to lead with gestures and instrument movements. 


\section{Methodological FRAME}

Performing musicians tend to spontaneously make quick observations and analysis of their own and fellow musicians' actions, which are immediately tested in practice. Therefore, the most important method to my artistic research is my own practice. In this study, I utilised practice-based research methods grounded on introspective first-person perception and reflexive comprehension to parse the phenomenon of my leading practice. My attempt to produce new knowledge about performancepractice through verbalising my own experience was influenced by the sensory interview method developed by Nummi-Kuisma (2010), who approached playing and interviewing as an intersubjective system to elicit and disclose a musician's implicit knowledge and to express it in a reflective-verbal form. In the current research, my fellow musicians, video recordings, rehearsal diaries and annotated scores served as the "interviewer", against which I reflected my intuitions and embodied knowledge about my leading actions and aspirations.

Using a practice-based method inspired by Nummi-Kuisma, I describe three case studies and some specific aspects that have emerged in my leading as a violinist. The piano quintet Spur (1998) by Austria-based Swiss composer Beat Furrer (born 1954) was the most difficult work to lead I had ever worked with, and I had to develop new leading techniques to manage the challenge. I performed Spur four times between 2009 and 2011. In this paper, I describe and reflect on the embodied knowledge I developed in the rehearsal and performance process of Spur. The most important reference material I use is the body knowledge I achieved in the rehearsals and performances by playing and discussing with the other musicians. I have returned to this work by reading the score, playing some excerpts and by giving presentations of my observations.

Vukovar Trio (1999) by American composer Laura Kaminsky (born 1956) included three rehearsals and a concert in 2019. I video-recorded all of the rehearsals and the concert, kept a rehearsal diary and made score annotations during the rehearsal process and discussed leading with the other musicians. I analysed the diary text and the video afterwards while preparing to write the current article. I combined three perspectives: the immediate observations made during the rehearsal process, the self-reflective perspective of the diary text and the outsider perspective of the video recording through which I could relive and analyse what happened in my leading.

"Pierrot" quintet (flute, clarinet, piano, violin, cello) Night Music (2014) by Serbian-Swedish composer Djuro Zivkovic (born 1975) involved three rehearsals and a concert in 2019. Immediate observations made during the rehearsals were reflected through the diary and score annotations, which I wrote during the rehearsal process. 
TRIO vsk. 10 nro 1 - Artikkelit: Maria Puusaari 40-64

\section{TEMPORAL LEADING AND WORKING WITH TIME SIGNATURES: BeAt FurRer's Spur}

Spur is a 17-minute-long virtuoso piece for a piano quintet (Ex. 1) that exemplifies complex musical material in which quickly changing time signatures, tempi, polyrhythms and extreme pianissimo dynamics make vertical, concurrent materials hard to perceive and coordinate.
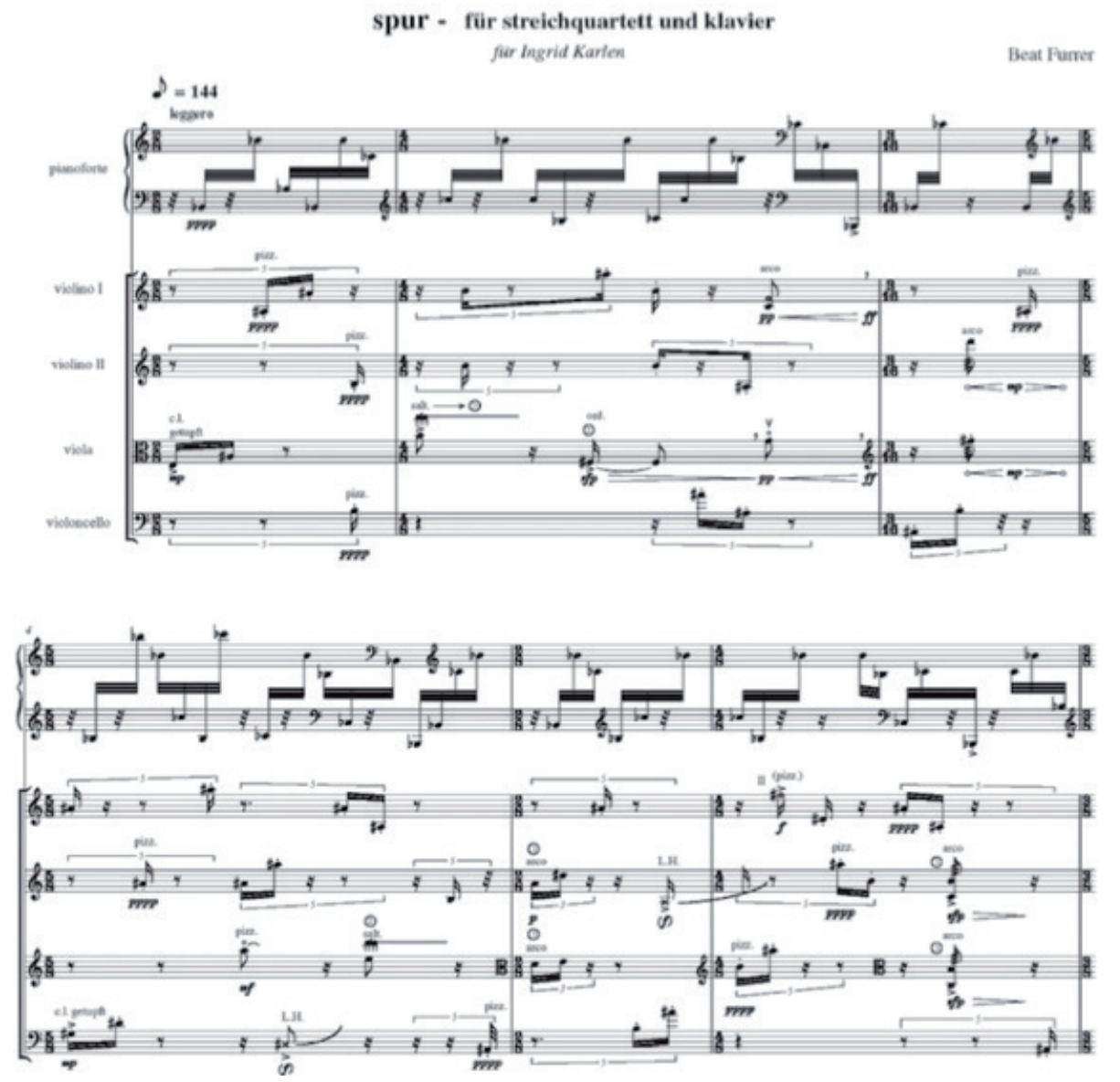

Example 1. Beat Furrer (1998) Spur, bars 1-6. Bärenreiter BA 7423.

Time signatures are constantly changing in Spur and must be clearly indicated. At the beginning of the work, I give two upbeats in tempo with the violin scroll, the weaker to the left and the stronger directly upwards. In the first $2 / 8$ bar there is only a downbeat and an upbeat. In the second $4 / 8$ bar I move the violin scroll for the first beat down, the second right, the third left and the fourth up. The third 3/16 bar is only one beat, where I measure my leading gesture by silently clicking my tongue 
in sixteenth notes. The gesture is bouncy and energetic to emphasise the longer and upward-rising beat. The fourth $5 / 8$ bar is divided into the first beat down, second beat almost at the same place as the first, third beat on the left, fourth beat on the right and fifth beat up.

Violinists' body movement strategies and styles depend on tempi (Coorevits et al. 2019,105-106). In Spur, the eighth note pulse is very fast, at M=144. In the fast tempi, the leader can express the "groove" in music by tightly-controlled and energetic body gestures and head nods. I lead with my left side since my left arm is making leading gestures by moving the violin in conducting patterns. I focus the leading gestures to the violin scroll and emphasise the upbeats and downbeats in particular by strong and rhythmic head nods.

I indicate forte dynamics with a bigger and stronger movement of the instrument. The clearly audible first beats in forte, such as bar 4 in the cello line as well as the first violin's two forte sixteenth notes in bar 6, are emphasised by articulating them explicitly. The score of Spur includes a plethora of commas. These short breaks serve as reference points to the ensemble and help to re-orientate for the next section. I show the cuts in commas through a little circulating movement of the violin scroll and an upright lift of my right elbow. Those movements together are also an ending gesture. Numerous details on interpretation and articulation have to be negotiated within the ensemble: the length of commas and fermatas and how to continue after them, the balance between the instruments, and the overall character of the work.

Synchronisation among musicians is also communicated visually. While musicians must concentrate on their parts, with the aid of peripheral vision, they are able to see the others' gestures as well. Visibility can be improved by making bigger and stronger leading gestures, turning the body towards or glancing at a specific musician to communicate details such as the beginning, rhythmic synchronisation, or dynamics. Direct eye contact is used in fermatas as a way to confirm that everyone is ready to continue. Otherwise, glances are very fast. As a leader I feel confident when I see even quick glances from the others because it indicates that we have a mutual understanding of our actions.

I have led Spur both in an established ensemble and in an ad hoc ensemble consisting of professional musicians. The pianist was the same in both groups.

In the ad hoc group, everybody had played contemporary chamber music but not together as an ensemble. We had five rehearsals before the performance in a music festival. Nobody had played Spur before. The roles and tasks had to be communicated more precisely than in the established group. As the first violinist, I was the leader, and since I had played a lot with the pianist, we took the main responsibility of leading in the beginning of the rehearsing process. The strength of the group was a very high rhythmic accuracy and a shared sense of pulse. My leading gestures drew feedback from the others by pulsating body gestures and instrument movements 
as well as supporting major upbeats or commas with head nods, breathing, facial expressions and eye contact.

Whether a string quartet stands or sits creates different bodily challenges and possibilities for each member in the group (Boyle 2015, 90). We decided to play in a standing position except for the cellist, who was sitting. Since he did not use a podium, he was not in the same line of vision with the other players. However, in a standing position, the sounds of the string instruments do not blend as well as in a sitting position since the resonance bodies and the F-holes of the violins and the viola are so much higher than those of the cello. Nevertheless, standing improved the overall visibility among the players and helped us to keep contact with the pianist, who was the most remote seated player in the group. Standing made leading easier since my body movements were not constrained by sitting on a chair. The ability to use my whole body and move my feet and hips allowed me to freely produce more power and variation in my leading gestures.

Later on, I performed Spur three times with the established ensemble. Rather than the conducted beat patterns, the ensemble wanted indications of upbeats and downbeats. However, I had to maintain the conducting pattern to be able to show the fast-changing time signatures and the beats in their correct directions. The members knew each other's playing styles, and the tasks within the group were clear. The cellist sitting opposite me worked as my co-leader, sharing the major upbeat leading by head nods and supporting the pulse by a rhythmic playing technique of the bow arm. The violist and second violinist shared leading in their rhythmicallysynchronised parts. The pianist used head nods to synchronise with the others. Since the pianist and I had already performed Spur once, the rehearsal process was faster.

\section{EXPRESSIVE LEADING WITH INTENTIONAL AND NON-INTENTIONAL GESTURES: LAURA KAMINSKY's VUKOVAR TRIO}

Laura Kaminsky composed Vukovar Trio after her visit to the war-torn city of $\mathrm{Vu}$ kovar, Croatia in 1997. The work is dedicated to the victims of the ethnic genocide of the Yugoslav Wars in the 1990s. The one-movement piano trio is connected by contrasting sections: "A Sky Torn Asunder", "The Shattering of Glass", "Lost Souls", "Revenge/Retreat", "Death Chorale", "River of Blood and Ice", "Ghost Chorale" and "Dance of Devastation". I played Vukovar Trio with an ad hoc trio. I had played many times with the cellist but never with the pianist. The cellist and the pianist play regularly together as a duo.

The tragic narrative of Vukovar Trio guided my interpretation, which immediately affected the power and the amplitude of the leading gestures at the beginning of the practice period: the dramatic passages facilitated more physical intensity and larger gestures, and the fragile character of "breathless" passages were emphasised by 
almost motionless body posture. The clear pulse and several unison rhythms made Vukovar Trio easy to lead. It was rather the music itself that was leading us since much of the information on synchronisation and expression was perceived aurally and reacted to by the auditory imagery, the ability to "hear ahead", that is, to anticipate the forthcoming musical situations (Keller \& Appel 2010, 28).

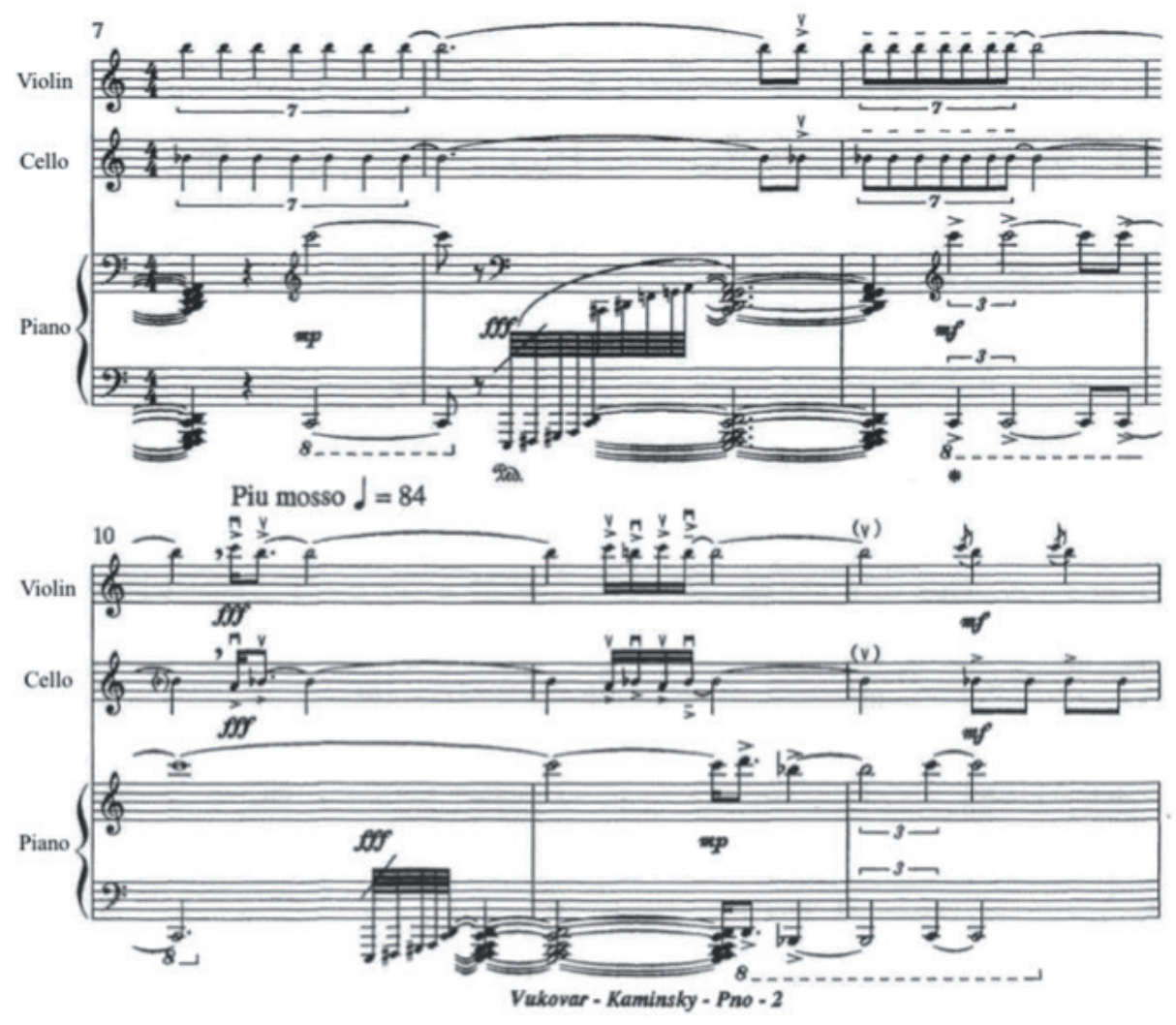

Example 2. Laura Kaminsky (1999) Vukovar Trio, "A Sky Asunder", bars 7-12. Distributed by Bill Holab Music.

In addition to producing sound, the violinists' bowing hand gestures may also function as cueing-in tempo (Bishop \& Goebl 2018, 102). Consciously-planned breathing helped me to measure the linearity and amplitude of the leading gestures and to express the character of the passages (see Boyle 2015,98). I used the bow movements and my right arm and elbow to "breathe"4 bow strokes rhythmically and to synchronise leading gestures with the temporal frame. The intention of the well-prepared bow

4 In this article, "breathing" in quotes means metaphorical breathing, such as "breathing" with a bowing gesture. Breathing without quotation marks refers to physical breathing. 
strokes was to help the other musicians to anticipate my leading actions.

In order to synchronise the unison rhythms between the cello and violin as in "A Sky Asunder" (Ex. 2), we looked at each other's bow movements to coordinate the similar use of the bow, articulation, speed and intensity. I emphasised the growing intensity from bar 7 to bar 12 by leaning my body forward. To confirm the start after the long notes, I gave pulsating nods during the last two crotchets of the long notes. In bar 10 (Ex. 2), there was a tempo change after the long note. I showed the short comma with a circular cutting gesture of the violin scroll, which at the same time included the upbeat in faster tempo. I breathed deeply and made a strong forward attacking gesture to indicate a strong upbeat and to synchronise the power peak in forte fortissimo dynamics. In bar 12, the dynamics suddenly dropped to mezzoforte, which I indicated with a smoother and smaller bodily gesture.

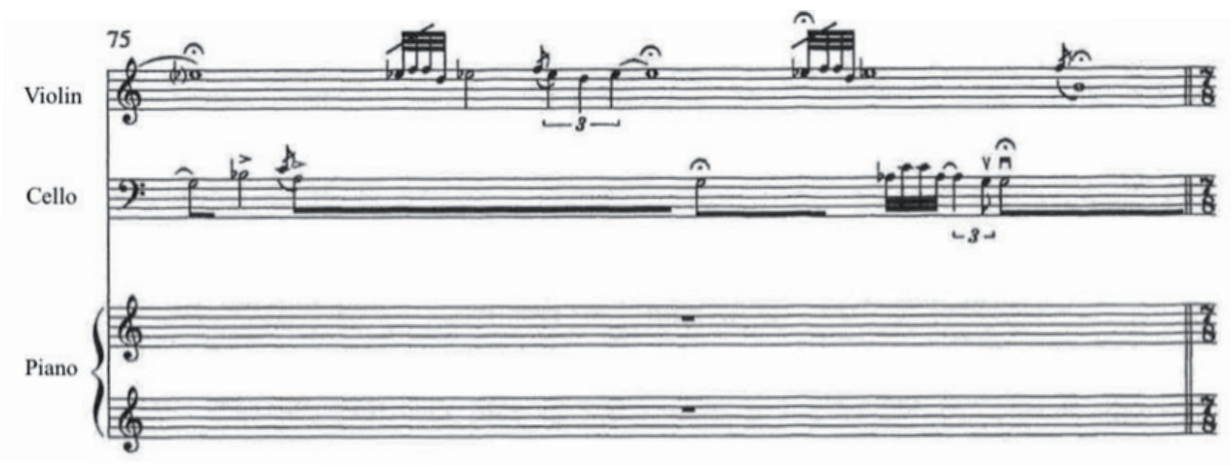

Example 3. Laura Kaminsky (1999) Vukovar Trio, "Lost Souls", bar 75. Distributed by Bill Holab Music.

Passages such as the duo "Lost Souls" (Ex. 3) do not need leading. The crotchet pulse is approximately $\mathrm{M}=60$, and the movement is to be played molto espressivo e rubato. There is no indication for dynamics, but mezzopiano diminuendo at the end of the previous movement as well as the sad and intimate character of the music call for soft dynamics. In the individual parts, music is printed out as a score and seeing the other parts helps with the synchronisation. Watching the video revealed how my body gestures were communicating the direction of phrases in an unintentional way. Similarly, I leant forward when playing the short notes and stood still during the long notes. My forward leaning and swaying gestures were small in the beginning but became more intense and gesturally articulated as the music gained intensity.

Arriving at specific notes such as the fermatas in bar 75 (Ex. 3) and timing the short musical gestures with the cello were also emphasised by a "placement of the beat" body gesture: a head nod and a bow stroke. After the fermatas, I leant forward to communicate the continuation and the direction of sound. My tactile sensation during the practice and the analysis of the video material afterwards indicated that 
since I did not have to lead or follow leading, I was moving more freely than during the other movements of the piece.

Leading rhythmic patterns while playing a long note can be heard as "counting beats", playing unintentional accentuated sounds during the long bow stroke (Ex. 4, bars 120-122). In my individual practice, I always prepared to lead everything, even though I had anticipated not needing to lead during the long notes in "Revenge/ Retreat".
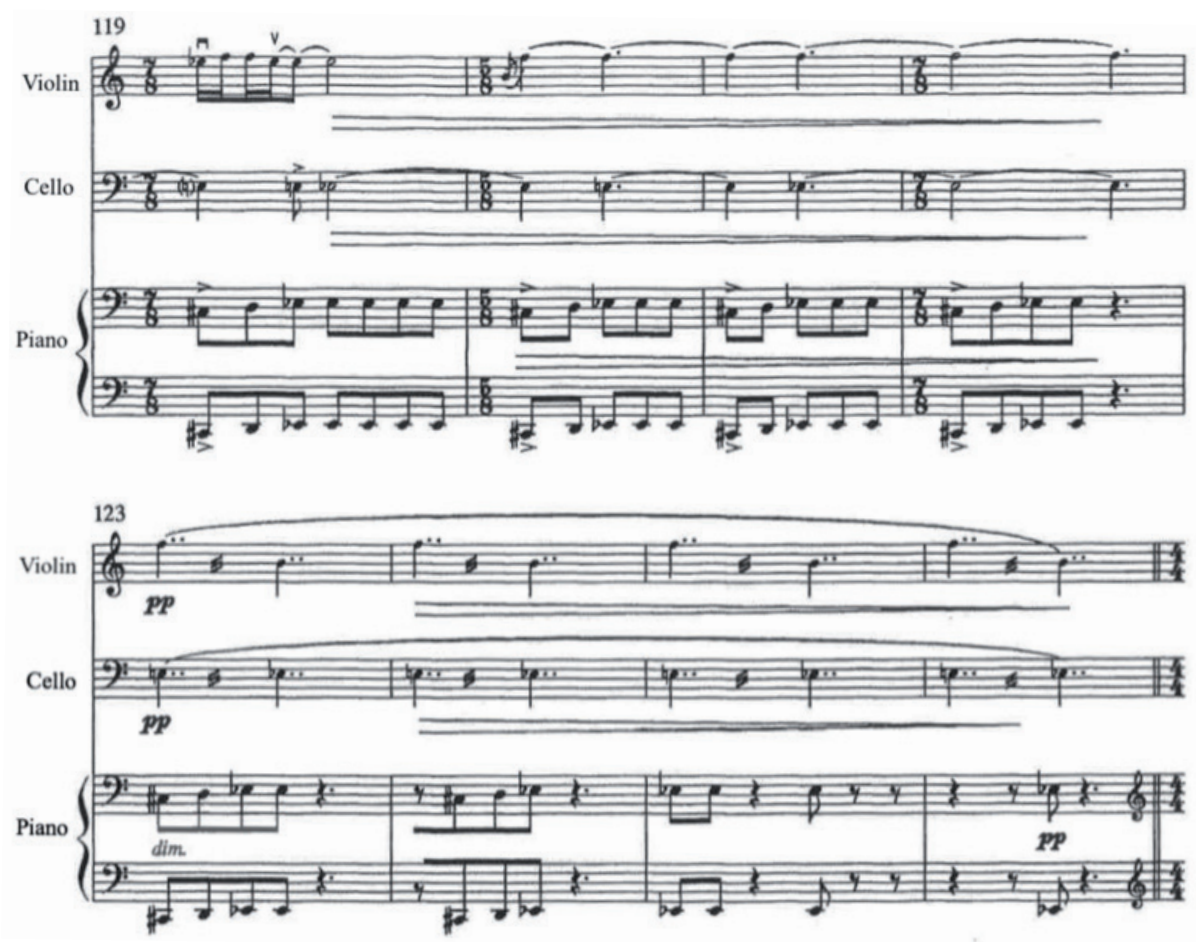

Example 4. Laura Kaminsky (1999) Vukovar Trio, "Revenge/Retreat", bars 119-126. Distributed by Bill Holab Music.

Indeed, in "Revenge/Retreat", the pianist and cellist shared leadership until bar 122 (Ex. 4, bars 119-122). The pianist's rhythmic hand gestures and the cellist's body gestures, head nods and short bow strokes indicated the accentuated forte eighth notes in the cello and piano lines. My attention was focused on my lines'lyrical quality while I simultaneously clicked eighth notes silently with my tongue and stamped crotchets and dotted crotchets lightly with my left foot to give a sense of the pulse and to synchronise the changing of the long notes with the other instruments (Ex. 4, bars 119-122).

Musicians are not trained to control our facial expressions; thus, we tend to reveal our intentions, actions and internal emotional states (Boyle 2015, 44; Davidson 
2012, 614, 623). Only when watching the video did I notice how I suddenly lifted my eyebrows and made a small nodding gesture on the upbeat before bar 123 (Ex. 4). This unconscious facial expression and physical gesture signified the beginning of the tremolo, the change of the character and the subtle alternation of the leadership (see Boyle 2015, 131): I took the leader's role after the pianist and the cellist.

\section{EXTENDED PLAYING TECHNIQUES IN LEADING - WITH OR Without conductor? DJuro Zivkovic's Night MUSIC}

Extended playing techniques put new demands on how to handle the instrument. Musicians may need to concentrate fully on how to make the correct movements to execute the expected technique. These can result in more difficult leading. Playing also includes accidental and uncommunicative movements that might cause a lack of synchronisation (Windsor 2011, 48). Thus, an ensemble has to learn to execute extended techniques together to be able to communicate via the correct gestures.

At first, I generally try to find out why certain passage feel difficult: is it due to a particular playing technique, an expression, or leading gestures? What kind of sound am I trying to achieve, and how can I combine it with a leading gesture? If a certain passage feels too difficult to lead, it may be possible to share the leading responsibility or to discontinue leading in that passage. Sometimes the challenges of the musical material and the lack of rehearsal time require a conductor to coordinate the ensemble and to accelerate the rehearsal process.

I played Night Music by Djuro Zivkovic with an established ensemble that had two new substitutes. We were sitting in a half circle in front of the piano: the violin and the cello opposite each other and the flute and the clarinet in the middle. The seating restricted visibility among the musicians. Since I was able to see everyone, I shared the main leadership with the flutist while the other musicians co-led with us.

Night Music has six short movements based on Aleksandr Scriabin's piano pieces. The Romantic piano texture is coloured by the other instruments' whistling and whispering sounds created by extended playing techniques and vocalisation. The tonal functions of the piano part were easy to follow by listening. Everybody had to breathe together with the piano part since the texture was full of rubatos and ritardandos.

In my rehearsal diary, I am constantly writing about how leading gestures are difficult to combine with some extended techniques and how leading becomes easier when playing together with the other musicians. For example, the bariolage technique in the fifth movement of Feuillet d'album No 2 Con delicatezza (Ex. 5) is played on two strings, with the first and fourth fingers of the left hand playing in unison throughout the whole movement. Thus, every change of note also entails a position shift. The bow is playing fast pianissimo tremoli on two strings, shifting between or- 


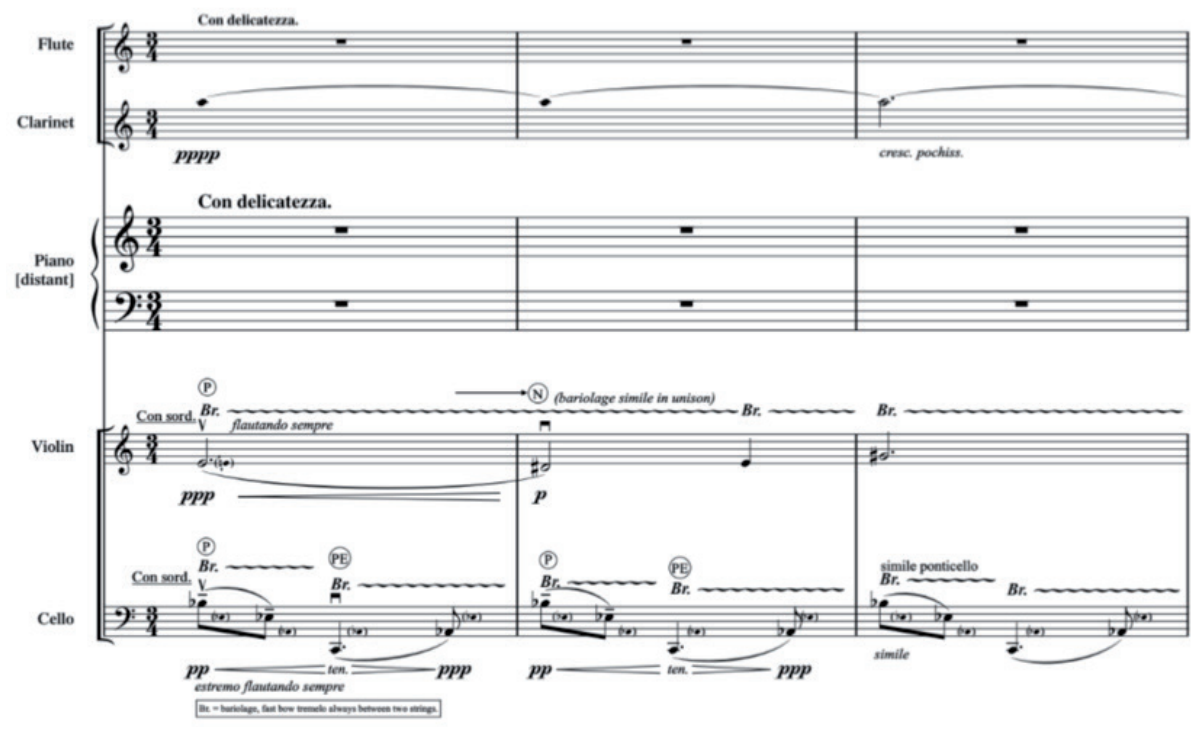

Example 5. Djuro Zivkovic (2014) Night Music, Feuillet d'album No 2, bars 1-3. Edition Octoechos SS-5115.

dinario and ponticello timbres. The extended distance between the left fingers makes the hand stiff and the changing of positions clumsy, while the legato bow technique is difficult to control towards the heel of the bow. Because the extended playing techniques demanded my full attention, I was not able to execute leading gestures, or to show the pulse, upbeats, or downbeats. This is a typical example of shared leadership and co-leading since the cellist took over the leadership by nodding the pulse and showing the upbeats.

In my diary, I describe how I tried to over-emphasise the leading gestures, characters and nuances of Night Music in the first rehearsal. During the rehearsal process my leading gestures began to feel lighter: I made rounder and smoother gestures to express the atmosphere in the music. We had one rehearsal with the composer on the concert day. Normally, during the meeting with the composer the musicians discuss technical or interpretative details and the composer provides her or his ideas of the sound and interpretation. In this case, we had the composer listening to the balance in the concert hall acoustics. As a result, many details changed: the composer wanted more distant sounds, including for the piano. Suddenly our temporal point of reference, the piano texture featuring Scriabin piano pieces, became inaudible. The piece had previously been played with a conductor, but this new setting was quite challenging because we were playing chamber music without a conductor and without being able to properly hear the auditory cues that 
we had learnt to listen for. I had to go back to the more visual and gestural leading, even though the ideal gestural vocabulary for the character of the work would have been a more delicate one.

\section{Discussion}

In the beginning of this article, I tried to explain the challenges and the special skill set required in leading contemporary music. I briefly reviewed the literature on leadership, interaction and gestural communication in ensemble-playing as well as the practice of leading and different ensemble roles. Through three case studies I explored the questions of leading techniques as they express different musical features and the musical and social aspects that affect leading in the context of contemporary music ensembles.

\section{Leading techniques}

Based on the evidence of the three case studies, I divide leading into temporal and expressive leading techniques according to their function in communicating temporal and expressive musical features. Both leading techniques include intentional and non-intentional gestures. Following the gesture categorisation provided by King and Ginsborg $(2011,179)$, leading gestures are a subset of communicative gestures. However, due to the multifunctional nature of performers' physical gestures, one can include sound producing, technical gestures and expressive gestures as communicative leading gestures. Next, I provide specific aspects of each leading technique and its gestural execution.

The core of my leading in these pieces was based on temporal leading technique, which indicates temporal musical features such as entries, exits, pulse, upbeats and downbeats, divided beat patterns, tempo and time change, and agogics. The leader must be able to indicate these features to help the ensemble coordinate its playing since, according to both literary as well as my own practice-based scrutiny, synchronisation and coordination are the primary purpose and concern of leading in a chamber music ensemble (Bayley 2011, 395; Gorton \& Östersjö 2020, 60-66). The most important musical features to be led were pulse, divided beat patterns and upbeats and downbeats, as in Beat Furrer's Spur (Ex. 1). The pulse was more stable and rhythms more accurate when the ensemble divided the beat patterns in a similar way (Ex. 1, Spur; Ex. 4, Vukovar Trio by Laura Kaminsky). That also helped the musicians to synchronise their gestures, which unified both sonic and visual information within the ensemble and made playing and leading easier (see also Boyle 2015,98 ). Temporal features were often combined in one multifunctional gesture, such as indicating pulse and beats and at the same time communicating agogics by leaning the body forward to push, leaning backwards to pull back, and stabilising 
the tempo with a steady body posture. A stable temporal frame allowed expressive musical features to emerge in leading.

When learning a new work, temporal leading of the rhythmic structure must be practiced from the very beginning of the rehearsal process. Thinking of an expression or a gesture activates the body (Nummi-Kuisma 2010, 102), and predictive gestural models and images regarding leading - the kinesthetic imagery (Leman 2016, 137-138) - helped me to anticipate and "sense" upcoming leading gestures. I read the score while playing and wrote cues for my part to anticipate what I should be listening for and looking at as reference information while playing. Leading as an "internal metronome" was also meant for myself to measure my playing actions. I dictated rhythms, sang some passages, stamped the pulse, silently clicked my tongue to divide the beats into smaller units and conducted the pulse and beating patterns without the violin. I practiced the work and leading gestures with and without the metronome in different tempi to create a body language to express the musical structure. I also practiced the work without leading to reduce the physical stress and to better concentrate on my violin playing. Leading can make playing rigid and painful especially in the beginning of the practice, which may cause problems later on with playing techniques or even interpretation. Therefore, the temporal leading technique must be consciously learned and embedded in one's body and personal playing style as one instrumental playing technique among many.

The repertoire has a great impact on leading gestures: a challenging contemporary music work including divided time signatures such as Beat Furrer's Spur (Ex. 1) requires conducting-like temporal leading techniques that always involve a great number of leading gestures by at least one musician. This kind of leading is close to an orchestral conductor's task; separate conducting studies on beating techniques and how to use them while playing would therefore help musicians to add urgently needed tools to their skill set, especially in the context of contemporary music ensembles.

In addition to temporal leading technique, expressive leading technique includes a combination of both intentional and non-intentional, multifunctional body gestures and postures, playing techniques, instrument movements and breathing to communicate expressive musical features such as direction of phrasing, characters and affects of music, dynamics, articulation and musical gestures. I often combined expressive leading technique with temporal leading, for example by giving an upbeat in a specific character or timing the leading gesture with the other musicians' phrasing and musical gestures.

In Laura Kaminsky's Vukovar Trio, the titles of the movements guided me to emphasise the musical narrative with expressive body and bow movements, which closely resembles the approach by Spissky $(2017,5.3)$ at a Gesturist performance. Rhythmic playing gestures drew more dynamic and expressive power from body swaying gestures that simultaneously freed the bow arm gestures and communi- 
cated tension, release and the direction of the phrasing. The "breathless" character of the music was expressed by a still, almost motionless body posture. Dynamics were emphasised with body postures such as leaning downwards to describe quiet dynamics or upwards to play out louder dynamics. Articulation and timbre were communicated by emphasised bow articulation, lifting the violin higher to indicate the use of vibrato or rhythmic activity of fingers. Affects and musical atmosphere were generally communicated by facial gestures. In general, playing with expressive cues is a powerful method to balance the ensemble and to communicate musical ideas during the performance both to fellow musicians and the audience (see King \& Ginsborg 2011, 179).

In Night Music by Djuro Zivkovic, rhythmic leading of the pulse was not always viable, so I had to relate my leading gestures to the agogics of the piano texture, which changed the character of my gestures. To enable leading with extended playing techniques, I also had to extend my leading technique and use unusual body gestures. Moreover, the leader's responsibility rotated within the ensemble when extended playing techniques constrained leading or required more supportive leading, which demands instrument-specific leading skills from every musician. Sometimes synchronisation of the ensemble demanded large and active leading gestures that were contradictory to the character of the music or the piano dynamics of my part (Ex. 5, Night Music). Larger gestures were needed as a point of reference to ensure coordination and to compensate for the lack of mutual hearing caused by the quiet dynamics and dry concert hall acoustics. However, larger gestures tend to manifest louder volume in the ensemble and therefore the musicians had to execute quiet dynamics extra carefully. To achieve a calmer gestural performance in Night Music (Ex. 5), for example, a conductor could have been employed to coordinate and balance the ensemble (see Holden 2003, 14).

\section{Factors affecting leading}

In addition to the two leading techniques just described, several other factors affected my leading in the multidirectional interaction with other musicians. Understanding their effect on leading may help to improve leading practices. First, I discuss sensorimotor and temporal aspects in leading, followed by acoustical, instrumentspecific, and socio-cultural aspects.

Musical material and instrumental affordances for a violinist set possibilities and limitations on leading. In principle, musicians'bodily movements tend to be strongly related to phrasing (Davidson 2012, 623; Demos et al. 2017, 16-17). Therefore, I often felt that leading the pulse and beat patterns was uncomfortable and contrary to the body's natural playing gestures (Ex. 1, Spur). In Vukovar Trio (Ex. 4), for instance, leading was impossible in a high register and while playing long notes. An attempt to lead in those passages would have disturbed the other musicians' synchronising their rhythmic material. Leading was even prevented due to the gestural 
requirements of extended playing techniques in Night Music (Ex. 5). A gesturebased approach to the practice of contemporary music may help clarify and execute leading gestures as gestural-sonic objects (see also Östersjö 2016, 476). Altogether, various instrumental and interactive affordances led to a conscious development of body articulation, leading techniques and strategies, including the equally important understanding of when to follow and not to lead.

The reactions to tempo indication varied in the different ensembles, with beginnings and phrase endings in particular tending towards tempo variations. When beginning to play a work, the musicians can communicate the tempo only by visual cues, which may cause different estimations of the starting tempo. This observation is in line with findings by Bishop and Goebl $(2018,103)$, who argue that due to the lack of auditory information, the beginning of the work is the most challenging moment to synchronise. Furthermore, musicians interpret their phrase endings differently, which may cause timing variations, such as slowing down the tempo while fellow musicians continue the phrase in tempo (see also Mota et al.2017,182-183). Timing culture, the relationship between leading and fellow musicians' reactions, is a cultural matter including a social, unspoken agreement on when to enter. One reason for different onset times in different ensembles was that as a leader I started to play before "the beat was at the bottom" and the leading gesture was complete. Followers' reactions require more time than the leading action: followers have to react to the leader's gesture, decode and interpret its content and then play their own part accordingly. As a leader, I should be a follower of my own leading as well.

In addition to sensorimotor and temporal aspects, various acoustical and instrument-specific aspects influenced my leading. The acoustics, the instruments' playing manners and different onset times have a great impact on the speed of the sound, which affected the musicians' reactions and timing. A violin played with a bow, for example, reacts and produces sound more slowly than a violin played by pizzicatos (see Blum 1987, 52). In Spur (Ex. 1), I had to relate my leading gestures to the time required to switch between the pizzicato and bow-playing techniques. In Night Music (Ex. 5), I had more predictive models and understanding of the string players than other instrumentalists' playing techniques, which affected my ability to understand the musicians' actions (see Boyle 2015, 98-99, 116-118; Ford \& Davidson 2003, 64). Furthermore, dry concert hall acoustics and quiet dynamics affected mutual hearing, sound projection and playing techniques in Night Music (Ex. 5), which increased the amount and amplitude of leading gestures, as suggested by MacRitchie et al. $(2017,155)$.

Along with the factors mentioned above, leading was influenced by several sociocultural aspects. The ensemble roles depended on the musical material and style of the work, the size of the ensemble and the experience and familiarity of the musicians with the piece. The aim was to "play together" (see Fink \& Merriell 1985, 22) since the musical material of the works demanded shared leadership and an active attitude 
from each ensemble member. However, in Spur (Ex. 1), for example, the roles were first clearly divided in leader-follower roles, which affected timing reactions (see Timmers et al. 2014, 7). In Vukovar Trio (Ex. 2, Ex. 3, Ex. 4), the musical material directed the leadership to rotate inside the ensemble (see Doğantan-Dack 2013, 282). In both quintets (Ex. 1, Spur; Ex. 5, Night Music), I had the main responsibility on leading, whereas the pianist, cellist and flutist had important roles as co-leaders (see also Ford \& Davidson 2003, 63; Heyde 2012). I had to lead and move more in the beginning of the practice period and with the new partners since I had to take the initiative to coordinate the group that had not yet identified its style of bodily interaction and gestural feedback. This is in line with results by Keller and Appel $(2010,41)$ who observed that the lack of coordinating cues increased the amplitude of musicians' body movements, which were used as references and feedback on coordination and timing. I tried to adjust the level of leading depending on the different needs of the group by giving more support for newcomers and requesting supportive leading from more experienced players. The gestural interaction and supportive co-leading increased with growing familiarity in the group, which made playing and leading easier. This confirms observations by King and Ginsborg (2011, 196): performers in singer-pianist duos used more physical gestures when rehearsing with same-expertise and familiar partners than with new and different-expertise partners. Indeed, familiarity and trust have great significance in ensemble playing, gestural interaction and working atmosphere (see Boyle 2015, 110; Good \& Davidson 2002, 188; King 2013, 266-268).

Progress in the rehearsal process affected leading requirements. In the first rehearsal, gestural cues had to be clear and the pulse had to be led throughout the work. Many details of leading gestures and shared leading responsibilities had to be negotiated verbally. As familiarity with the music and co-performers' parts and playing styles grew, synchronisation gradually became more based on the auditory information and leading became merely supportive. Sometimes leading gestures were minimal: musicians intuitively sensed and audibly perceived delicate changes in music, and gestures were not needed to emphasise all the details. However, the intensified atmosphere of a live performance may affect the amplitude and the quantity of leading gestures, which could be either increased or reduced, or even disappear altogether. Some of this musical knowledge is learned only onstage (DoğantanDack 2013, 279) and therefore, a live performance is an important part of developing a coherent leading technique. Developing a personal body language for leading practices requires time and practice with other musicians in a variety of works also through live performances. 


\section{Conclusion}

Leading is a very personal skill, and there may be as many ways to lead as there are leaders. In this article I have articulated the significance of this fundamental embodied skill necessary for contemporary music performance from my personal viewpoint and practice. There is need for more practice-based research on this subject, however, especially from different instrumentalists' points of view. Studies on subjective leading techniques, different team roles and leading extended playing techniques in diverse ensemble contexts could provide practical innovations and valuable information on the performance-practice and teaching of contemporary music. I hope that this study adds to the growing body of knowledge in this area. 


\section{REFERENCES}

ScORES

Furrer, Beat 1998. Spur - für klavier und streichquartett. Kassel, Germany: Bärenreiter BA 7423.

Kaminsky, Laura 1999. Vukovar Trio. New York, USA: Bill Holab Music.

Zivkovic, Djuro 2014. Night Music. Bandhagen, Sweden: Edition Octoechos SS-5115.

RESEARCH LITERATURE

Bayley, Amanda 2011. Ethnographic research into contemporary string quartet rehearsal. Ethnomusicology Forum, 20(3), 385-411. https://doi.org/10.1080/17411912.2011.645626

Bishop, Laura, \& Goebl, Werner 2018. Beating time: How ensemble musicians' cueing gestures communicate beat position and tempo. Psychology of Music, 46(1), 84-106. https://doi.org/10.1177/0305735617702971

Blum, David 1987. The Art of Quartet Playing. The Guarneri Quartet in conversation with David Blum. Ithaca, New York: Cornell University Press.

Boyle, Caitlin McCaffery 2015. The Influence of Nonverbal Communication Processes in String Quartet Performance. Canada: University of Toronto. Unpublished Doctoral thesis. ProQuest Dissertations Publishing 3746220.

Caruso, Giusy, Coorevits, Esther, Nijs, Luc, \& Leman, Marc 2016. Gestures in contemporary music performance: A method to assist the performer's artistic process. Contemporary Music Review, 35(4/5), 402-422. https://doi.org/10.1080/07494467.2016.1257292

Coorevits, Esther, Moelants, Dirk, Maes, Pieter-Jan, \& Leman, Marc 2019. Exploring the effect of tempo changes on violinists' body movements. Musica Scientiae, 23(1), 87-110. https://doi.org/10.1177/1029864917714609

Davidson, Jane W. 2012. Bodily movement and facial actions in expressive musical performance by solo and duo instrumentalists: Two distinctive case studies. Psychology of Music, 40(5), 595-633. https://doi.org/10.1177/0305735612449896

Demos, Alexander P., Chaffin, Roger, \& Logan, Topher 2017. Musicians body sway embodies musical structure and expression: A recurrence-based approach. Musica Scientiae, 22(2),1-20. https://doi.org/10.1177/1029864916685928

Doğantan-Dack, Mine 2013. Familiarity and Musical Performance. In E. King \& H. M. Prior (eds.) Music and Familiarity. Listening, Musicology and Performance. Surrey, England: Ashgate. 271-288.

Fink, Irving, \& Merriell, Cynthia 1985. String Quartet Playing. Neptune City, N.J: Paganiniana Publications.

Ford, Luan, \& Davidson, Jane W. 2003. An investigation of members' roles in wind quintets. Psychology of Music, 31(1), 53-74. https://doi.org/10.1177/0305735603031001323

Gilboa, Avi, \& Tal-Shmotkin, Malka 2010. String quartets as self-managed teams: An interdisciplinary perspective. Psychology of Music, 40(1),19-41.https://doi.org/10.1177/0305735610377593

Good, James M., \& Davidson, Jane W. 2002. Social and musical co-ordination between members of a string quartet: An exploratory study. Psychology of Music, 30(2), 186-201. https://doi.org/10.1177/0305735602302005

Gorton, David, \& Östersjö, Stefan 2019. Austerity Measures I: Performing the discursive voice. In C. Laws \& W. Brooks, D. Gorton, N. Thanh Thuy, S. Östersjö \& J. J. Wells (eds.) Voices, Bodies, Practices Book Subtitle: Performing Musical Subjectivities. Belgium: Leuven University Press. 29-79. https://doi.org/10.1177/1029864916685928

Gorton, David, \& Östersjö, Stefan 2020. Negotiating the discursive voice in chamber music. In C. Laws (eds.) Performance, Subjectivity, and Experimentation. Belgium: Leuven University Press. 53-78. https://doi.org/10.2307/j.ctvmd83kv.6 
Griffiths, Paul 2011. Modern Music and After. $3^{\text {rd }}$ Edition. New York, USA: Oxford University Press.

Heyde, Neil 2012. Quartet Choreography. Kreutzer Quartet. DVD. Cambridgeshire, UK: Divine Art Limited.

Holden, Raymond 2003. The technique of conducting. In J. A. Bowen (ed.) The Cambridge Companion to Conducting. United Kingdom: Cambridge University Press. 3-16.

Huovinen, Erkki, \& Rautanen, Heli 2020. Interaction affordances in traditional instruments and tablet computers: A study of children's musical group creativity. Research Studies in Music Education, 42(1), 94-112.

Johnston, Ben 2006. Musical intelligibility. Where are we? 1963. In B. Gilmore (ed.) Maximum Clarity and Other Writings on Music. Urbana and Chicago, USA: University of Illinois Press. 91-102.

Keller, Peter, \& Appel, Mirjam 2010. Individual differences, auditory imagery, and coordination of body movements and sounds in musical ensembles. Music Perception: An Interdisciplinary Journal, 28(1), 27-46. https://doi.org/10.1525/mp.2010.28.1.27

King, Elaine C. 2006. The roles of student musicians in quartet rehearsals. Psychology of Music, 34(2), 262-282. https://doi.org/10.1177/0305735606061855

King, Elaine 2013. Social Familiarity: Styles of Interaction in Chamber Ensemble Rehearsal. In E. King \& H. M. Prior (eds.) Music and Familiarity. Listening, Musicology and Performance. Surrey, England: Ashgate. 253-270.

King, Elaine, \& Ginsborg, Jane 2011. Gestures and Glances: Interactions in Ensemble Rehearsal. In A. Gritten \& E. King (eds.) Nerw Perspectives on Music and Gesture. Surrey, England: Ashgate. 177-201.

Leman, Marc 2016. The Expressive Moment. How Interaction (with Music) Shapes Human Empowerment. Cambrigde, MA: MIT Press.

Lipinaityte, Ruta 2014. The orchestra concertmaster as a polyfunctional figure. International Journal of Liberal Arts and Social Sciences, 2(7), 67-74.

MacRitchie, Jennifer, Varlet, Manuel, \& Keller, Peter E. 2017. Embodied Expression through Entrainment and Co-representation in Musical Ensemble Performance. In M. Lesaffre, P-J. Maes \& M. Leman (eds.) The Routledge companion to embodied music interaction. New York, NY: Routledge. 150-159.

McElheran, Brock 1966. Conducting Technique for Beginners and Professionals. New York: Oxford University Press.

Mota, Davi, Loureiro, Mauricio, \& Laboissière, Rafael 2017. Gestural Interactions in Ensemble Performance. In M. Lesaffre \& P-J. Maes \& M. Leman (eds.) The Routledge companion to embodied music interaction. New York, NY: Routledge. 177-185.

Murnighan, J. Keith, \& Conlon, Donald E. 1991. The dynamics of intense work groups: A study of British string quartets. Administrative Science Quarterly 36, 165-186. https://doi.org/10.2307/2393352

Nummi-Kuisma, Katariina 2010. The attunement of a pianist in performance. Intersubjective, systemic and psychoanalytical view on playing a virtuoso etude. [In Finnish]. Doctoral dissertation. Helsinki: Studia Musica 43, Sibelius-Academy.

Spissky, Peter 2017. Ups and Downs, Violin Bowing as Gestures. Lund University, Sweden. Doctoral thesis. http://www.upsanddowns.se

Timmers, Renee, Endo, Satoshi, Bradbury, Adrian, \& Wing, Alan M. 2014. Synchronization and leadership in string quartet performance: a case study of auditory and visual cues. Frontiers in Psychology, 5(1), 1-9. https://doi.org/10.3389/fpsyg.2014.00645

Windsor, Luke W. 2011. Gestures in Music-making: Action, Information and Perception. In A. Gritten \& E. King (eds.) New Perspectives on Music and Gesture. Surrey, England: Ashgate. 45-66. 
TRIO vsk. 10 nro 1 - Artikkelit: Maria Puusaari 40-64

Young Vivienne M., \& Colman Andrew M. 1979. Some psychological processes in string quartets. Psychology of Music, 7, 12-16. https://doi.org/10.1177/030573567971002

Östersjö, Stefan 2016. Go to hell: Towards a gesture-based compositional practice. Contemporary Music Review, 35(4/5), 475-99. https://doi.org/10.1080/07494467.2016.1257625 